\title{
An Occupational Health Study of the Footwear Manufacturing Workers of Kolkata, India
}

\author{
Somnath Gangopadhyay, Tarannum Ara, Samrat Dev, Goutam Ghoshal and Tamal Das \\ Occupational Ergonomics Laboratory, Department of Physiology, University College of \\ Science and Technology, University of Calcutta, 92, A. P. C. Road, Kolkata 700 006, \\ West Bengal, India
}

KEYWORDS Leather Industry. Respiratory Diseases. Peak Expiratory Flow Rate

ABSTRACT The footwear industry occupies a place of prominence in the Indian economy in view of its massive potential for employment, growth and exports. Footwear workers are exposed to a plethora of occupational hazards of which the most hazardous one is from industrial adhesives and glues. The adhesives and glues cause various respiratory diseases, neurotoxicity and cancer. Peak Expiratory Flow Rate (PEFR) values are helpful in identifying and assessing the degree of air flow limitations of individuals and it can be measured using relatively portable and inexpensive Peak Flow Meter. In this study an attempt was made to identify the influence of occupation on the health of workers engaged in footwear industries of Kolkata. For this purpose the Experimental Group involved in various manufacturing processes and the Control Group of the same strength involved only in stitching jobs from the same footwear manufacturing unit were randomly selected. The statistical analysis of physical parameters of both the groups showed no significant difference between these parameters, which established the fact that the subjects of both groups belong to the same range of age, weight, height and BSA. But the statistical evaluation of PEFR of experimental group and the control group showed significant result, with the control group exhibiting higher values. From the present observation it may be concluded that dust particles and adhesives affect the lung capacity and PEFR of the footwear manufacturing workers irrespective of their type of work.

\section{INTRODUCTION}

The footwear industry is a significant segment of the leather industry in India. India ranks second among the footwear producing countries next to China (Szubert et al. 2001). The industry is labour intensive and is concentrated in the small and cottage industry sectors. The footwear industry in West Bengal comprises mainly cottage or tiny to small scale sector. The sector directly and indirectly employs about 10 lakh workers. The footwear industry of Kolkata is worth Rs.3, 000 crores (Kolkata Newsline 2006).

There are several processes involved in footwear making like Measuring, Last making, Pattern cutting, Sewing, Assembling and Finishing. Each of these processes is associated with different types of health hazards. But most insidious of all are toxic organic solvents present particularly in adhesives and also in the hardeners, cleaning solutions and degreasers used in shoe-making processes. The workers are ex-

Address for correspondence:

Dr. Somnath Gangopadhyay

13, Katua Kuthi Lane,

Bhawanipur, Kolkata 700 025,

West Bengal, India

Telephone: 913324558792

Fax: 913323509755

E-mail: ganguly1961@yahoo.com posed to chemicals like leather dust, benzene (used as solvent in glues) and $p$-tert butyl phenols (used in neoprene adhesives). Thus, most of them suffer from respiratory problems, lung diseases and skin infections through constant exposure to glues and fumes. Acute poisoning of these adhesives may lead to respiratory and cardiovascular failure and death (Tiwari 2005). The study by Zuskin et al. (1996) on footwear manufacturing workers showed that atmospheric pollution in the shoe manufacturing industry may be responsible for the development of acute and chronic respiratory impairment. Lung function severity increased with duration of employment. The study by Paggiaro et al. (1985) showed clinical and functional respiratory features of workers of three shoe factories exposed to organic solvents from glue or other adhesives. The study revealed that occupational exposure to large amount of glue solvents in shoe factory might cause chronic airway impairment with non-specific bronchial hyper responsiveness.

Lung function is influenced by such factors as sex, age, height, weight, environment and ethnicity (Anyanwu and Umeh 1989; Mashalla et al. 1992). Lung function test provides a clearer understanding of pulmonary function in subjects of different races, age, sex, occupation and profession. If there are functional abnormali- 
ties in the respiratory system, the deviation from normal can form a basis for diagnosis and assessment of progress in the management of chronic ventilatory diseases (Ali 1983).

Peak Expiratory Flow Rate (PEFR) is an important parameter to measure resistance and severity of airflow obstruction and in the management of bronchial asthma. It is helpful in distinguishing obstructive from restrictive pulmonary disorders. In asymptomatic cases it may be the only means of diagnosis. It can also point out specific trigger factors for asthma (Mehta 2000). Many studies on PEFR in the general population have been carried out previously in India (Gangopadhyay and Mahapatra 1998; Vijayan et al. 2000; Raju et al. 2003; Qureshi et al. 2004; Raju et al. 2004) and abroad (Nku et al. 2006) and it was observed that age, sex and smoking habits have a definite role in lowering ventilatory capacity.

In order to determine if the measured values are pathological or not, they must be compared with prediction equations. Usually the prediction equations for spirometric variables are based on age and height, stratified for sex. Men have on an average higher lung function values than women, of the same age and height. Lung function decreases with age and increases with height. A tall subject will therefore have higher lung volume than a short subject of the same age. The outcome from prediction equations may differ considerably between different reference populations. The variation in age and height in the reference population will also influence the predicted values. This means, for example, that a prediction equation must not be used if age and/or height for the examined subject are outside the ranges for the population that is the basis for the prediction equation (Ulfvarson and Dahlqvist 1998).

\section{METHODOLOGY}

Selection of Subjects: The present study was performed in the month of November, 2009. For this study, from five different manufacturing units, 20 male (20 to 30 years of age) footwear manufacturing workers were randomly selected from Kolkata, West Bengal as Experimental group. These workers performed various jobs of manufacturing namely measuring, cutting, applying adhesives, fitting job and finishing. In Control group, 20 male subjects of the same age group (20 to30 years), having same range of height (155 to $175 \mathrm{~cm}$ ), weight (40 to $70 \mathrm{~kg}$ ), BSA (1.43 to $1.68 \mathrm{~m}^{2}$ ) and year of experience of (8 to 10 years) were selected. The subjects of Control group were involved only in stitching jobs required for footwear making processes belonging to the same footwear manufacturing units as the Experimental group. They never do any kind of work involving glues or adhesives. All the subjects included in this study resided within the same locality; their monthly income was within the range of Rs. 2000 to Rs. 2250. Both the Experimental and Control groups were involved in the footwear manufacturing job and most of them were illiterate or at the most had attended school up to standard 3 or 4 . So from the above observation we can say that both the groups belonged to the same socio-economic status residing in the same area.

A questionnaire was performed to know the health status of all the subjects. The questionnaire included questions about their present, previous history of respiratory and cardiac problems and also history of other diseases. Those having family history of the above mentioned problems were excluded from the study. All the subjects included in this study resided outside their respective footwear manufacturing factories within $1.5 \mathrm{~km}$. All of them reached their factories by walking.

Measurement of Physical Parameters: The stature and weight of the Experimental group and Control group were measured by Martin's Anthropometer and weighing machine (Crown, Mfg. by Raymon Surgical Co.) respectively. The Body Surface Area (BSA) (Bannerjee and Sen 1955) of all the subjects was also computed.

Measurement of Peak Expiratory Flow Rate (PEFR): PEFR is one of the useful and simple parameters in the field for assessing the lung function status in general population and also for making a diagnosis and monitoring treatment of patients with bronchial asthma and chronic obstructive lung disease (Prasad 2006).

Measurement of PEFR was done with the help of a Wright's mini peak flow meter (Mfg. by Clement Clarke). Prior to recording PEFR of subjects, the use of the instrument was repeatedly demonstrated and explained. The PEFR test was performed in standing position holding the peak flow meter horizontally. Subjects were asked to take in a deep breath as far as possible and then blow out as hard and as quickly as possible. The highest of the three ratings was recorded. The predicted PEFR Indian values of 
Table 1: Analysis of questionnaire performed on both the experimental and control groups $(\mathrm{N}=20)$

\begin{tabular}{|c|c|c|c|c|c|}
\hline & & \multicolumn{2}{|c|}{ Experimental group } & \multicolumn{2}{|c|}{ Control group } \\
\hline \multirow{2}{*}{\multicolumn{2}{|c|}{$\begin{array}{l}\text { Regular working hour } \\
\text { No. of working days in a week }\end{array}$}} & \multirow{2}{*}{\multicolumn{2}{|c|}{$\begin{array}{c}12.7 \\
6\end{array}$}} & \multirow{2}{*}{\multicolumn{2}{|c|}{$\begin{array}{c}12.7 \\
6\end{array}$}} \\
\hline & & & & & \\
\hline & & Responses & Percentage & Responses & Percentage \\
\hline \multirow[t]{3}{*}{ Type of transport to reach factory } & By walking & $5 \min$ & $10(50 \%)$ & $5 \min$ & $12(60 \%)$ \\
\hline & & $10 \mathrm{~min}$ & $5 \quad(25 \%)$ & $10 \mathrm{~min}$ & $6(30 \%)$ \\
\hline & & $15 \mathrm{~min}$ & $5 \quad(25 \%)$ & $15 \min$ & $2(10 \%)$ \\
\hline \multirow[t]{3}{*}{ Type of hazard at workplace } & Dust & - & $-\quad-$ & - & \\
\hline & Fume & - & $-\quad \quad-$ & - & \\
\hline & Both & Yes & $20(100 \%)$ & Yes & $20(100 \%)$ \\
\hline \multirow[t]{2}{*}{ Respiratory problems } & Asthma & Yes & $4(20 \%)$ & Yes & $2(10 \%)$ \\
\hline & $\begin{array}{l}\text { Other specify } \\
\text { (Regular cough) }\end{array}$ & Yes & $2(10 \%)$ & - & - \\
\hline \multirow[t]{2}{*}{ Cardiac problems } & Hypertension & Yes & $2(10 \%)$ & - & - \\
\hline & Other specify & - & $-\quad \quad-$ & - & \\
\hline Suffocation & & Yes & $20(100 \%)$ & Yes & $20(100 \%)$ \\
\hline Eye irritation & & Yes & $20(100 \%)$ & Yes & $20(100 \%)$ \\
\hline Nausea & & Yes & $20(100 \%)$ & Yes & $20(100 \%)$ \\
\hline Dizziness & & Yes & $20(100 \%)$ & Yes & $20(100 \%)$ \\
\hline
\end{tabular}

Mehta (2000) were used in the present study. These predicted values were compared with the observed values of experimental and control groups of identical age, height and sex.

Statistical Analysis: Student “t” test was performed to establish the fact that both the selected groups belong to the same range of physical parameters and also to find out the significant difference between observed and predicted PEFR of both the groups. Percent deviation of their mean observed PEFR from their predicted PEFR of both the groups was also calculated (Das and Das 2005).

\section{RESULTS}

Occupational diseases are mainly caused due to improper management of the occupational health of the workers. Occupational diseases cover all pathological conditions induced by prolonged work, for example, by excessive exertion or exposure to harmful factors inherent in materials, equipment or the working environment.

When the subjects of both the groups were asked about their health status they said that whenever adhesives or glues were used during making of footwear, all of them felt problems like suffocation, eye irritation, nausea and dizziness. Table 1 represents the responses to the questionnaire on their health status. The subjects of Experimental group also said that the feeling of above mentioned problems is so strong that they have to go out of the workplace for some time to get back to normal self.

In Table 2, student's t test was performed between age, height, weight and BSA of the Experimental group and Control group. The result shows that there is no significant difference between these parameters, which establishes the fact that the subjects of Experimental group and Control group belong to the same range of age, weight, height and BSA. But the statistical evaluation of PEFR of Experimental group and the Control group showed significant results.

Table 2: Statistical evaluation of different parameters between the experimental and control group $(\mathrm{N}=20)$

\begin{tabular}{|c|c|c|c|c|}
\hline $\begin{array}{l}\text { Para- } \\
\text { meters }\end{array}$ & $\begin{array}{l}\text { Experi- } \\
\text { mental } \\
\text { group } \\
\text { (Mean } \\
\pm S D)\end{array}$ & $\begin{array}{l}\text { Control } \\
\text { group } \\
\text { (Mean } \\
\pm S D)\end{array}$ & $t$ & Remarks \\
\hline Age (yr) & $\begin{array}{r}24.4 \\
( \pm 3.63)\end{array}$ & $\begin{array}{r}26.3 \\
( \pm 3.00)\end{array}$ & 1.804 & $\begin{array}{l}\text { Not significant } \\
\mathrm{P}=0.67\end{array}$ \\
\hline $\begin{array}{c}\text { Weight } \\
\text { (kg) }\end{array}$ & $\begin{array}{r}49.1 \\
( \pm 4.35)\end{array}$ & $\begin{array}{r}50.5 \\
( \pm 13.30)\end{array}$ & 0.412 & $\begin{array}{l}\text { Not significant } \\
P=0.68\end{array}$ \\
\hline $\begin{array}{l}\text { Height } \\
\text { (cm) }\end{array}$ & $\begin{array}{r}163.4 \\
( \pm 4.46)\end{array}$ & $\begin{array}{r}163.0 \\
( \pm 5.13)\end{array}$ & 0.229 & $\begin{array}{l}\text { Not significant } \\
\mathrm{P}=0.07\end{array}$ \\
\hline $\begin{array}{l}\mathrm{BSA} \\
\left(\mathrm{kg} / \mathrm{m}^{2}\right)\end{array}$ & $\begin{array}{r}1.57 \\
( \pm 0.073)\end{array}$ & $\begin{array}{r}1.58 \\
( \pm 0.096)\end{array}$ & 0.371 & $\begin{array}{l}\text { Not significant } \\
\mathrm{P}=0.89\end{array}$ \\
\hline $\begin{array}{l}\text { PEFR } \\
\text { (liter/min) }\end{array}$ & $\begin{array}{r}389 \\
( \pm 89.90)\end{array}$ & $\begin{array}{r}493 \\
( \pm 52.12)\end{array}$ & 4.476 & $\begin{array}{l}\text { Significant } \\
\mathrm{P}=0.001\end{array}$ \\
\hline
\end{tabular}

It is further observed that the footwear manufacturing workers have much lower PEFR values than expected (Table 2). The predicted PEFR of Experimental group is significantly higher than the observed value. The predicted PEFR of control group workers working in the same footwear unit is also significantly higher than the observed value. This observation is in cor- 
roboration with the study of Zuskin et al. (1996), where they observed that the measured ventilatory capacity values in exposed workers were significantly lower in comparison with the predicted values. From the above result it may be suggested that occupational exposure to atmospheric pollution in the footwear manufacturing industry may be responsible for the development of acute and chronic respiratory impairment. On further statistical evaluation of percent deviation of mean observed PEFR from mean predicted PEFR, it is observed that in Experimental group it is 28.2 percent whereas in Control group it is 9.12 percent. This shows that irrespective of being within the same range of physical parameters, the PEFR of the Experimental group is lower than the Control group (Table 3).

Table 3: Statistical relationship of PEFR between Experimental group and Control group $\mathbf{N}=\mathbf{2 0}$

\begin{tabular}{|c|c|c|c|c|c|}
\hline Subjects & $\begin{array}{l}\text { Expec- } \\
\text { ted } \\
\text { PEFR } \\
\text { (liter/ } \\
\text { min) } \\
\text { (Mean } \\
\pm S D)\end{array}$ & $\begin{array}{l}\text { Obser- } \\
\text { ved } \\
\text { PEFR } \\
\text { (liter/ } \\
\text { min) } \\
\text { (Mean } \\
\pm S D)\end{array}$ & $t$ & Remarks & $\begin{array}{l}\% \\
\text { Devi- } \\
\text { ation }\end{array}$ \\
\hline $\begin{array}{l}\text { Experi- } \\
\text { mental } \\
\text { group }\end{array}$ & $\begin{array}{l}541.8 \\
\pm 17.47\end{array}$ & $\begin{array}{l}389.0 \\
\pm 89.9\end{array}$ & 7.462 & $\begin{array}{l}\text { Significant } \\
\mathrm{P}=0.000\end{array}$ & 28.2 \\
\hline $\begin{array}{l}\text { Control } \\
\text { group }\end{array}$ & $\begin{array}{l}542.5 \\
\pm 18.92\end{array}$ & $\begin{array}{l}493.0 \\
\pm 52.12\end{array}$ & 3.362 & $\begin{array}{l}\text { Significant } \\
\mathrm{P}=0.000\end{array}$ & 9.12 \\
\hline
\end{tabular}

This study shows the fact that both the subject groups are affected by the harmful effects of glues and adhesives used in footwear making processes and their effect is not localized. But the mean PEFR value and percent deviation of Experimental group (389 liter/min, 28.2\%) and Control group (493 liter/min, 9.12\%) shows that the Experimental group is much more affected than the Control group. This further establishes the fact that the work involving use of glues in various shoe making processes may be responsible for the development of acute and chronic respiratory impairment among the workers.

\section{DISCUSSION}

Workers generally perform jobs whose primary functions are cutting, gluing, sewing, dyeing, buffing or polishing of various parts of the shoe. In addition to the risks to those workers who manufacture shoes, similar risks are incurred by individuals who repair shoes by using the same chemical or mechanical processes. The greatest risk for occupational exposures occurs in the gluing process, when workers may be exposed to various solvents. Under specific circumstances, these chemicals may be associated with the development of medical illness. The other risk may be the exposure to leather dust in the cutting areas. The study by Acheson et al. (1982) shows that leather dust results primarily from cutting, grinding and polishing processes in shoe manufacturing, and this causes pulmonary toxicity and nasal carcinoma.

Exposures to the toxic solvents used in adhesives and cleaners and to airborne leather dusts are of particular concern. The study by Szadkowska et al. (2003) on health effects of occupational exposure among shoe workers provided evidence that employment in the shoe production and repair plants is associated with an enhanced risk for cancer by leather dust, as well as among non-neoplasms, diseases of the musculoskeletal system associated with ergonomic factors, contact dermatitis, chronic pulmonary diseases and damage of peripheral nerves in solvent-exposed workers are diagnosed.

The occupational exposures to chemicals (volatile organic solvents, isocyanates and water-based adhesives) in footwear industry could have adverse health effects on the workers (Todd et al. 2008). Isocyanates can cause asthma and other lung problems, even with very low exposure levels. Isocyanates can also irritate the eyes, nose, throat and skin of the exposed person.

Exposure to indoor air pollutants has been associated with serious health hazards such as acute respiratory infection (ARI), chronic bronchitis, asthma and lung cancer (Abdallah et al. 2010). The severity of the direct effect of indoor air pollutants on respiratory system varies according to the intensity and the duration of exposure, as well as the health status of the exposed population (Özdilli et al. 2007). Shoe workers could potentially be a high exposure group to air pollutants during their working hours (Bae 2004). Shoe-making is a labor-intensive process that involves exposure to a number of hazardous compounds, such as shoedust (leather), volatile organic compound, adhesives and shoe polish, hydrocarbons and different gases. 
The workers from both the groups work for an average of 12.7 hours a day and six days a week So from the present observation it may be concluded that dust particles and adhesives affect the lung capacity and PEFR of the footwear manufacturing workers irrespective of their type of job, that is whether or not their work involves exposure to leather dust and toxic adhesives both the groups are effected.

\section{CONCLUSION}

From the present study it may be concluded that the workers who are engaged in different footwear manufacturing activities, which involve exposure to leather dust and various toxic adhesives in the working environment have significantly lower peak flow rate than their predicted PEFR value. It seems that inhalation of the leather dust and toxic adhesives during work cause deposition of small particles along the lining of alveoli that decreases the venti-lationperfusion ratio and thus reduces the lung capacity and the PEFR value with height, age and weight.

\section{ACKNOWLEDGEMENT}

The authors express their sincere gratitude to all those Footwear Manufacturing Workers who rendered immense co-operation during the completion of this study.

\section{REFERENCES}

Abdallah HM, Hussein AS, Latif NMA, Hussein JS, Hassanien MA 2010. Ventilatory function and oxidative- antioxidant Status in shoe makers. Researcher, 2: 59-66.

Acheson ED, Pipped EC, Winter PD 1982. Nasal cancer in the Northamptonshire boot and shoe industry: Is it declining? Br J Cancer, 46: 940-949.

Ali MAR 1983. Ventilatory function in non-smoking healthy Nigerian adults. West Afr J Med, 2: 1-8.

Anyanwu CH, Umeh BU 1989. Ventilatory pulmonary function study in healthy young Nigerian adults. Afr J Med Sci, 18: 257-262.

Bannerjee S, Sen RN 1955. Determination of the surface area of the body of Indians. J of Appl Physiol, 7: 585-588.

Bae H, Yang W, Chung M 2004. Indoor and outdoor concentrations of RSP, NO2 and selected volatile organic compounds at 32 shoe stalls located near busy roadways in Seoul, Korea. Science of the Total Environment, 323: 99-105.

Das D, Das A 2005. Statistics in Biology and Psychology. Calcutta: Academic Publishers.

Gangopadhyay S, Mahapatra JK 1998. Pulmonary function studies on clinically normal Indian steel plant workers. Ind J of Physiol and Allied Sc, 52: 49-52.
Qureshi KA, Hassan G, Masoodi MA, Khan GQ 2004. Peak expiratory flow rates among Gujjar and non- Gujjar population of Kashmir Valley. J K Science, 6:84 - 87.

Kolkata Footwear Industries up in Arms against VAT. Kolkata Newsline, Express News Service, Kolkata, March 21, 2006. From <http://cities.expressindia.com/city.php>. (Retrieved on August 8, 2007).

Mashalla YJ, Mesesa PC, Veenekalaas RJ 1992. Changing relationship between $\mathrm{FEV}_{1}$ and height during adolescence. East Afr Med J, 69: 240-24.

Mehta P 2000. Peak expiratory flow rate. Bombay Hosp J, 42: 62-63.

Paggiaro P, Lastrucci L, Di Pede C, Bacci E, Rossi O, Talini D 1985. Respiratory pathology caused by exposure to solvents in the shoe industry: Description of 3 clinical cases. G Ital Med Lav, 7: 149.

Nku CO, Peters EJ, Eshiet AI, Bisong SA, Osim EE 2006. Prediction formulae for lung function parameters in females of south-eastern Nigeria. Nigerian Journal of Physiological Sciences, 21: 43-47.

Özdilli K, Issever H, Özyildirim BA, Hapçioglu B, Ince N et al. 2007. Biological hazards in tannery workers indoor and built. Environment, 16: 349-357.

Prasad R, Verma SK, Agrawal GG, Mathur N 2006. Prediction model for peak expiratory flow in north Indian population. The Ind J of Chest Dis and Allied Sc, 48: 103-106.

Raju PS, Prasad KV, Ramana YV, Ahmed SK, Murthy KJ 2003. Study on lung function tests and prediction equations in Indian male children. Indian Pediatric, 40: 705-11.

Raju PS, Ramana YV, Murthy KJ 2004. Pulmonary function tests in Indian girls: Prediction equation. Indian $J$ Pediatr, 71: 893-897.

Szadkowska SI, WoŸniak H, Stroszejn MG 2003. Health effects of occupational exposure among shoe workers. A review, Med Pr, 54: 67-71.

Szubert Z, Wilczynska U, Sobala W 2001. Health risk among workers employed in rubber footwear plant. Med Pr, 52: 409.

Tiwari RR 2005. Child labour in footwear industry: Possible occupational health hazards. Ind J of Occ and Exp Med, 9: 7-9.

Todd L, Puangthongthub ST, Mottus K, Mihlan G, Wing S 2008. Health survey of workers exposed to mixed solvent and ergonomic hazards in footwear and equipment factory workers in Thailand. Ann Occup Hyg, 52 :195-205.

Ulfvarson U, Dahlqvist M 1998. Encyclopaedia of Occupational Health and Safety. Geneva: International Labour Office. (http://books.google.co.in/books? $\mathrm{id}=\mathrm{vW} 6 \mathrm{rXF}$. 4 s Q C \& p g = PA 1960 \& lpg $=$ PA $1960 \& d q=L U N G+F U N C T I O N+E X A M I$ NATION,+Ulf+Ulfvarson,+Monica+Dahlqvist \&source=bl\&ots=MGM1EfxYra\&sig=ZpB3q MeQEav0EsHrN3ZSU58wqNA\&hl=en\#v= onepage\&q=LUNG\%20FUNCTION\%20EXAMI NATION\%2C\%20Ulf\%20Ulfvarso n\%2C\%20Monica $\% 20$ Dahlqvist\&f=false) (Retrieved on January 11, 2011).

Vijayan VK, Reetha AM, Kuppurao KV, Venkatesan P, Thilakavathy S 2000. Pulmonary function in normal south Indian children aged 7-19 years. Indian J Chest Dis Allied Sci, 42: 147-56.

Zuskin E, Mustajbegovic J, Doko-Jeliniæ J, Kern J, Bradiæ V 1996. Respiratory symptoms, diseases and ventilatory function in shoe industry workers. Arh Hig Rada Toxic, 47: 189-97. 